\title{
EL PANÓPTICO COMO MODELO DE PODER EN LA NOVELA EL SEÑOR PRESIDENTE DE MIGUEL ÁNGEL ASTURIAS
}

\author{
Daniel Rojas Pachas \\ Universidad de Tarapacá \\ carrollera@gmail.com
}

\begin{abstract}
Resumen
La presente investigación, inspirada por el concepto foucaultiano de panóptico, analiza al interior de la novela El señor Presidente, las relaciones de poder como manifestaciones de un discurso acorde a una estructura logocéntrica de vigilancia y denuncia. El estudio busca además verificar la vigencia de la obra considerando dentro de la realidad continental representada, la presencia del panóptico como mecanismo coercitivo de control capaz de normalizar la identidad de los individuos y determinar las relaciones políticas e interpersonales.
\end{abstract}

Palabras Clave: vigilancia, logocentrismo, panóptico, disciplina, poder.

\begin{abstract}
The current research inspired by Foucault's concept of panopticon, analyzes within the novel The Mister President the power relationships as a manifestation of a speech ruled by a logocentric structure of surveillance and denunciation. The work also studies the relevance of this text considering the presence of the panopticon in the represented continental reality as a coercive mechanism of control capable of normalizing the identity of the individuals and determine the political and interpersonal relationships.
\end{abstract}

PaLABRAS CLAVE: surveillance, logocentrism, panopticon, discipline, force.

\section{Introducción}

RA Fundamentalmente, este trabajo estudia el texto en su nivel pragmático, considerando la sociedad disciplinaria que Asturias propone al enfocar el tema del poder como una sutil maquinaria de vigilancia que se ajusta a los principios y características del panóptico: diseño arquitectónico carcelario, ideado por el pensador británico Jeremy Bentham a fines del siglo XVIII y que el filósofo postmoderno Michel Foucault, revisita teóricamente, en cuanto a sus implicancias psicosomáticas. Esta lectura por tanto, busca analizar la estructura de poder y vigilancia comunicada por medio del discurso de los narradores y actantes, aplicando las consideraciones postmodernas que Foucault realiza sobre el panóptico en su entrevista El ojo del poder y en la obra Vigilar y castigar. El modelo arquitectónico de Jeremy Bentham se aborda en torno a sus implicancias socio 
políticas a fin de verificar cómo el principio de transparencia y visibilidad y demás elementos constitutivos del diseño carcelario operan en la edificación de un panóptico latinoamericano, el cual al interior de la obra cumple el rol de tecnología del dominio y sustento material de un sistema que procura normalizar a cada individuo y organizar íntegramente el cuerpo social del portal del Señor.

El mecanismo de poder literariamente advertido por el autor guatemalteco, se encuentra plasmado en las voces que cruzan la novela, lo cual permite conocer al lector, dispuesto a dialogar extensionalmente con la obra, una lógica de sumisión e imperio jerárquico propio de las sociedades disciplinarias. Esta última aseveración nos aproxima además a un juicio con respecto a la pertinencia que mantiene la lectura hecha por Asturias, al tratar el tema del poder dentro de la realidad continental, más allá de lo estético surrealista y el tipo humano conocido como dictador.

\section{El panóptico: sustento del poder en el señor Presidente}

Si pensamos en la realidad plasmada por Asturias, la grotesca ciudad del portal del Señor se desenvuelve como una comunidad latinoamericana de principios del siglo pasado, inmersa en las perspectivas planteadas por Foucault para explicar el orden y ejercicio del poder tanto a nivel global como local. Se trata de un mundo regido por la disciplina y vigilancia, estructurado bajo el imperio de tecnologías que se ajustan al principio de transparencia que impone el panóptico. El concepto de este diseño, una torre de recámaras laberínticas situada en una posición central rodeada de celdas transparentes, permite a un vigilante observar (-opticón) a todos (pan-) los prisioneros sin que éstos puedan saber si están siendo vistos o no, bastaría con esta percepción constante de vigilancia para que cada uno, sintiéndola pesar sobre sí, terminara por interiorizarla hasta el punto de vigilarse a sí mismo. Cumpliéndose así, bajo tan sencillo principio de visibilidad y transparencia, la necesidad de control tanto global como individualizante.

Empero, hay que destacar que la novela, al tratarse de una historia de dictadura, presenta la maquinaria social desvirtuada producto del ejercicio abusivo que encarna el señor presidente como supremo y presente titular del panóptico. El fundamento de su potestad se halla estructurado por el conjunto de redes civiles y militares que domina. Estas lo ubican en lo más alto del gobierno y jerarquía central que sirve de núcleo de vigilancia. Desde allí, valiéndose del anonimato, la infidencia y traición, el presidente tanto como sus coroneles y caudillos, los que a su vez pretenden acceder al título supremo o al menos apropiarse de una porción del poder; conocen y dirigen de manera íntegra los pormenores de la vida de los pobladores y subyugados (verdaderos reclusos ubicados en periféricas celdas transparentes). El siguiente pasaje de la novela resulta ilustrativo:

Los habitantes, iguales en el espejo de la muerte, como desiguales en la lucha que reanudarían al salir el sol; unos sin lo necesario, obligados a trabajar para ganarse el pan, y otros con lo superfluo en la privilegiada industria del ocio: amigos del Señor 
Presidente, propietarios de casas - cuarenta casas, cincuenta casas-, prestamistas de dinero al nueve, nueve y medio y diez por ciento mensual, funcionarios con siete y ocho empleos públicos (Asturias 1999, p. 9).

En la obra como en el modelo de sociedad extraliterario, quien encabeza y dirige los hilos de la estructura de vigilancia establece las normas y mecanismos de ejecución del poder, tal como indica Foucault en Vigilar y castigar:

Este espacio cerrado, recortado, vigilado, en todos sus puntos, en el que los individuos están insertos en un lugar fijo, en el que los menores movimientos se hallan controlados, en el que todos los acontecimientos están registrados, en el que un trabajo ininterrumpido de escritura une el centro y la periferia, en el que el poder se ejerce por entero, de acuerdo con una figura jerárquica continua (Foucault 1998, p. 201).

El siguiente pasaje transcrito detalla este proceder en la novela:

- Demasiado te he dicho que me disgusta que congenies con toda la gente. No hay que dar esperanzas. ¿Cuándo entenderás que no hay que dar esperanzas? En mi casa, es que no se dan esperanzas de ninguna especie a nadie. En estos puestos se mantiene uno porque hace lo que le ordenan, y la regla de conducta del Señor Presidente es no dar esperanzas y pisotearlos y zurrarse en todos porque sí. Cuando venga esa señora le devolvés su papelito bien doblado y que no hay tal saber dónde está enterrado su marido (Asturias 1999, p. 135).

Esas palabras en boca del auditor de guerra, un personaje que administra la justicia bajo un discurso centralizado e inflexible, confirma el espíritu imperante dentro de las relaciones formales de ley y orden expuestas en la realidad ficticia. Suerte de indeterminación en los castigos y falta de debido proceso. Lo que a su vez, asumido como constante por la ciudadanía, sirve para condicionarlos psicológicamente. Los detentadores del poder son una fuente de terror reverencial que se reconoce como tal:

Ambos agregaron con el pensamiento "cometer un delito", por ejemplo (...) "ultrajar públicamente a las personas indefensas" o "hacer sentir la superioridad de la fuerza sobre la opinión del país" o "enriquecerse a costillas de la Nación" o... El delito de sangre era ideal; la supresión de un prójimo constituía la adhesión más completa del ciudadano al Señor Presidente. Dos meses de cárcel, para cubrir las apariencias, y derechito después a un puesto público de los de confianza (Asturias 1999, p. 101).

El orbe ciudadano por su parte, demuestra en su acatamiento mecánico e inconsciente los peligrosos extremos del modelo, capaz de conducir las conciencias y extender sus dominios al ámbito íntimo del remordimiento y la vergüenza. A fin de visualizar este aspecto del poder, es preciso analizar a dos figuras que resultan simbólicas dentro de la obra, pues cada una representa dentro de la sociedad del portal del Señor, más allá de los esteriotipos, dos ideologías y formas de vida contrapuestas. El sacristán y el estudiante carecen de nombre y mayor descripción, pero cada uno en su carácter 
alegórico remite respectivamente a un marcado proceder moral y voluntad de acción. El primero se cobija en el estoicismo cristiano y la sumisión ante designios superiores, mientras que su contraparte, remite a una racionalidad disidente y cáustica:

¿Adonde volver los ojos en busca de libertad? El sacristán: -¡A Dios, que es Todopoderoso! El estudiante: -¿Para qué, si no responde? El sacristán: -Porque ésa es Su Santísima voluntad... Es mejor rezar... El estudiante: -¡Qué es eso de rezar! ¡No debemos rezar! ¡Tratemos de romper esa puerta y de ir a la revolución!” (Asturias 1999, p. 116).

La importancia de estas dos voces en el texto no es menor, pues en ellas se personaliza la dualidad político-religiosa del texto tal como señala Caridad L. Silva de Velázquez: "Un estudio cuidadoso de la obra y sus discursos, demuestra la constante asociación del tema religioso al tema político, y revela además la importancia del primero como complemento del segundo"(Silva de Velásquez 1977, p. 708). Indistintamente, ambas vertientes ante el porvenir, resignación y resistencia, sufren por parte del medio la misma suerte: incomunicación y condicionamiento. De modo que su participación va nutriendo las connotaciones omnipotentes y omnipresentes de lo que para unos es un dictador, caudillo despótico y para otros, un esperpéntico Dios terrenal, figura mítica encarnada por este demiurgo con facultades omnímodas. Al respecto, vale la pena destacar un diálogo que sostienen una vez libres, al contemplar las ruinas apocalípticas del Portal del Señor. Esa conversación cierra el libro, y demuestra cómo la vigilancia y anonimato repercuten sobre el cuerpo, pero más importante aún, penetran en las expectativas y conciencias:

-No les bastó pintar el Portal a costillas de los turcos; para que la protesta por el asesinato de el de la mulita no dejara lugar a dudas, había que echar abajo el edificio... -Deslenguado, vea que nos pueden oír. ¡Cállese, por Dios! Eso no es cierto... (Asturias 1999, p. 164).

Aquel miedo que invoca a Dios como último recurso del pueblo junto a la resignación encarnada en el hombre de fe, se complementa con la imagen que presencia el estudiante al llegar a su hogar y ver a su madre suplicando con rosario en mano, producto de este purgatorio mundano:

El estudiante llegó a su casa, situada al final de una calle sin salida y, al abrir la puerta, cortada por las tosecitas de la servidumbre que se preparaba a responder la letanía, oyó la voz de su madre que llevaba el rosario: -Por los agonizantes y caminantes... Por los que sufren persecución de justicia (...) Por las benditas ánimas del Santo Purgatorio... (Asturias 1999, p. 165 los destacados son míos).

Efecto dogmático e ideológico, que impone sutilmente el poder del vigilante. Ante semejante callejón sin salida, el único paliativo seguro para los ignorantes y desvalidos habitantes de la periferia, es la piedad muda y etérea de una mirada constante y superlativa que sirve de directriz de los destinos, emane esta, del señor presidente o en su defecto del etéreo Dios cristiano. Foucault plantea al respecto: 
La mirada va a exigir pocos gastos. No hay necesidad de armas, de violencias físicas, de coacciones materiales. Basta una mirada. Una mirada que vigile, y que cada uno, sintiéndola pesar sobre sí, termine por interiorizarla hasta el punto de vigilarse a sí mismo; cada uno ejercerá esta vigilancia sobre y contra sí mismo (Foucault 1980, p. 6).

\section{El anónimato y transparencia como herramientas tecnológicas de dominio}

Es importante analizar además cómo al interior de la maquinaria de poder diseñada por Asturias, vigilantes y vigilados se relacionan y comunican en todo nivel; social, personal y político, bajo un clima de insidia, traición y denuncia, el cual opera en honor al paradigma logocentrista de observación anónima. Foucault plantea:

No se puede confiar en nadie cuando el poder está organizado como una máquina que funciona según engranajes complejos, en la que lo que es determinante es el puesto de cada uno, no su naturaleza. (...) En el Panóptico, cada uno, según su puesto, está vigilado por todos lo demás, o al menos por alguno de ellos; se está en presencia de un aparato de desconfianza total (...) La perfección de la vigilancia es una suma de insidias (Foucault 1980, p. 7).

Se trata, por ende, de una ilusión de poder a la que todos aspiran y frente a la cual proceden de forma consciente o indirecta, en concordancia con los elementos del diseño arquitectónico propuesto por Bentham. Si atendemos a los principios fundantes del panóptico, la mirada anónima y constante resulta un factor indispensable en la constitución del modelo, esto también se halla presente en la perspectiva latinoamericana que Asturias nos entrega en su novela. Tal condición queda implícita en el control que en beneficio del Presidente realizan en primer lugar su círculo interno de informantes. Su sistema de inteligencia, poder judicial y policial:

Un hombre menudito, de cara argeñada y cuerpo de bailarín, escribe sin levantar la pluma ni hacer ruido -parece tejer una telaraña: "Excelentísimo Señor Presidente, Constitucional de la República- (...)

Conforme instrucciones recibidas, síguese minuciosamente al general Eusebio Canales. A última hora tengo el honor de informar al Señor Presidente que se le vio en casa de uno de los amigos de su Excelencia, del señor don Miguel Cara de Ángel (Asturias 1999, p. 38).

En un segundo grado, las informaciones son remitidas por parte de la comunidad civil. Esto se explica debido al ánimo que existe en los habitantes, a fin de salir de la reclusión marginal en que los envuelve su celda transparente. Los ciudadanos, más allá de cualquier posición social o económica, aspiran a ubicarse en un nivel de control y vigilancia al interior de la torre o núcleo de poder. De esta manera se perfilan en su rol de eventuales guardias y agentes indirectos del sistema. Sutil forma de condicionamiento 
psicológico que prima en una sociedad de este tipo, instando a la sucesión de denuncias sin remitente.

A fin de detallar cómo funciona en la obra el mecanismo de intriga anónimo, es valioso remitirse de lleno al capítulo titulado "El parte al Señor Presidente". En él se nos da a conocer una serie de cartas de denuncia y petición que llegan desde la periferia a manos del regidor, pudiéndose destacar que de dieciséis comunicados expuestos de forma discreta, diez son alusiones directas a coroneles del ejército. Posibles enemigos y eventuales usurpadores del poder central. Los nombres marcados son: Carvajal, Canales y Farfán que dentro de la historia, si bien parten como hombres de confianza; debido a su creciente popularidad y caudillismo, terminan como blancos de una intriga que busca su encarcelamiento y eliminación, en lo posible sin proceso. Las denuncias que sirven para alimentar el encono y las medidas en contra de los falsos imputados se dan con motivo de ganarse el favor del Presidente. Pues más allá de la veracidad de las acusaciones, estas vienen redactadas con una seguridad de facto y a modo de misivas elogiosas:

"1.- Alejandra, viuda de Bran, domiciliada en esta ciudad, propietaria de la colchonería La Ballena Franca, (...) figura que en esa fonda está escondido el general Eusebio Canales, por las conversaciones que ha escuchado a través del muro, y que la personas que allí llegan conspiran contra la seguridad del Estado y contra la preciosa vida del Señor Presidente" (Asturias 1999, p. 89).

Otras cartas llegan incluso desde los más inesperados rincones. De parte de amantes y despechadas prostitutas:

“14.- Adelaida Peñal, pupila del prostíbulo El Dulce Encanto, de esta ciudad, se dirige al Señor Presidente para hacerle saber que el mayor Modesto Farfán le afirmó, en estado de ebriedad, que el general Eusebio Canales era el único general de verdad que él había conocido en el Ejército y que su desgracia se debía al miedo que le alzaba el Señor Presidente a los jefes instruidos; que, sin embargo, la revolución triunfaría" (Asturias 1999, p. 90).

Incluso las misivas, que no aluden directamente a los enemigos del orden central, no dejan de estar vinculadas a tormentos aberrantes, prisión y vejaciones, producto de las más insignificantes causas. De esta forma, ya sea por amenazas o insidias, así como por su propio actuar que los ubica como adherentes o detractores del poder central, se suceden y rotan de manera alternativa, en cuanto a preferencia, los vigilantes de la torre. Este proceso de movilidad al interior del panóptico permite afirmar que la calidad de guardia está única y exclusivamente garantizada en pro de los beneficios que el usuario brinda al sistema o, en este caso, por los servicios que presta al que detenta la posición jerárquica superior (el presidente).

En cuanto a la situación de los actantes principales, Miguel Cara de Ángel, sicario y mano derecha del regidor, el coronel Eusebio Canales, el coronel Farfán y los auditores de justicia, posicionados dentro de la torre y privilegiados frente a sus pares situados en la periferia del poder, podemos afirmar que no están libres en lo absoluto 
de la aparición de otro que procure usurpar su lugar, lo cual promueve la descarnada competitividad, deslealtad, infidencia y control mutuo entre guardias. Transcribo el siguiente texto de Foucault acerca del panóptico y que ilustra claramente lo expuesto:

Sin duda esto es lo que hay de diabólico en la idea como en todas las aplicaciones a que ha dado lugar. No existe en ella un poder que radicaría totalmente en alguien y que ese alguien ejercería él solo y de forma absoluta sobre los demás; es una máquina en la que todo el mundo está aprisionado, tanto los que ejercen el poder como aquellos sobre los que el poder se ejerce. (...) El poder, se convierte en una maquinaria de la que nadie es titular" (Foucault 1980, p. 6).

\section{El panóptico y la disolución de identidad}

El caso más representativo en la novela en cuanto a expropiación del poder se detalla en la degradación que sufre el protagonista, Miguel Cara de Ángel, al perder sus privilegios y supremacía jerárquica ante sus pares vigilantes; todas evidentes consecuencias de una íntegra disolución de identidad, tan solo por posicionarse de espaldas al sistema y contra su lógica. Aun cuando en un principio el sicario aparece como el favorito del señor Presidente, ubicado en la torre de poder, en un peldaño inmediatamente inferior al regidor, la forma en que el sistema diluye su identidad se hace inevitable dada su traición a la lógica y principios de la maquinaria. Esta degradación opera transformando su calidad de símbolo y detentador de la mirada central a víctima de una agonía imposible de ser rastreada. El castigo se impone a través de la reclusión en un panóptico privado. Celda constituida por la mirada de un único vigilante anónimo que informa al presidente sobre el deterioro gradual del prisionero hasta su muerte por putrefacción

(...) La partida de defunción del calabozo número diecisiete se asentó así: N.N.: disentería pútrida. Es cuanto tengo el honor de informar al Señor Presidente (Asturias 1999, p. 163).

Su calidad de víctima ejemplar del sistema al cual sirvió se complementa con la idea de rotación y calidad desechable de los vigilantes. Hay que destacar, además, la aplicación del mecanismo de suplantación que el Presidente realiza al ubicar en su lugar a un personaje idéntico a Cara de Ángel.

Un individuo con la cara disimulada en un pañuelo surgió de la sombra, alto como Cara de Ángel, pálido como Cara de Ángel, medio rubio como Cara de Ángel; apropióse de lo que el sargento arrancaba al verdadero Cara de Ángel (pasaporte, cheques, argolla de matrimonio - por un escupitajo resbaló dedo afuera el aro en que estaba grabado el nombre de su esposa-, mancuernas, pañuelos...) Y desapareció enseguida (Asturias 1999, p. 154).

Ocupando sus documentos oficiales y pertenencias, el suplantador cumple en el extranjero y ante el mundo la función de mano derecha encargada al original. En definitiva, se 
confirman los postulados expuestos en torno al modelo de poder y la manipulación que se hace del mismo, pues la inminente y estrepitosa caída del favorito está determinada por la inversión que el personaje hace en torno al principio regidor del mecanismo. La visibilidad y transparencia ejecutada a través de la mirada, se transforma en Cara de Ángel ante la presencia de Camila y lo que ella pasa a significar como alteridad ante la que el sicario es voluntariamente responsable.

-Es usted bondadosísimo...

-No, mayor, no debe agradecerme nada; mi propósito de salvar a usted está ofrecido a Dios por la salud de una enferma que tengo muy, muy grave. Vaya su vida por la de ella.

-Su esposa, quizás... (...) Al marcharse el mayor, Cara de Ángel se tocó para saber si era el mismo que a tantos había empujado hacia la muerte, el que ahora, ante el azul infrangible de la mañana, empujaba a un hombre hacia la vida (Asturias 1999, p. 102).

La valoración positiva de la mujer y eventual cónyuge no solo amenaza la forma de organizar el poder por ser Camila hija del coronel Eusebio Canales, el principal enemigo del Presidente. La trasgresión de fondo es menos anecdótica y va en contra de todo el sistema y su constitución, pues la mirada, instrumento básico del panóptico tal como Sartre lo concibe, es además el ámbito primero que abre la puerta a la comunicación. El otro nos es presente de un modo manifiesto en la experiencia de la mirada. Por tanto, cuando alguien nos mira, estamos ante otra subjetividad, otra conciencia y no un mero objeto; el otro se nos hace presente, por tanto podemos temer que se enfrente a nuestros proyectos, a nuestra libertad. Estamos indefectiblemente delante de un ser con el que podemos contar, o al que nos hemos de oponer. Delante de una percepción que nos valora o socava lo que somos. Por ello, más allá de la mirada instrumental o cosificadora que el mecanismo exige, la relación evolutiva de Camila y Cara de Ángel va resquebrajando en cuanto a confidencialidad y comunicación, aquella mirada inicial que los unía en un sistema de vigilancia y sumisión. El sicario pasa consecutivamente de secuestrador y carcelero, a amigo y benefactor, para luego convertirse solo en amante y compañero bajo una mirada intersubjetiva, que reconoce al otro como sujeto. Por extensión, la brecha que nace como una necesidad íntima y personal de ayudar a Camila se impone por sobre el discurso logocéntrico y se torna en una búsqueda intersubjetiva de un otro mayor (el cuerpo social). La mirada pasa a cumplir otra función, una consciente y libre, no deseada por el poder central, pues desde el reconocimiento subjetivo del otro, se implica un autoconocimiento que desemboca en la formación de una identidad propia, reflexiva e independiente de cualquier discurso condicionante y dirigido.

Cara de Ángel nace al mundo fuera del sistema jerárquico, y comprometido se responsabiliza en la tarea de subsanar la relación de sumisión que ejercía sobre su entorno. En términos materiales y prácticos podemos observar que el cambio implica una serie de acciones indirectas que van en contra del sistema, a la par que van delineando una nueva actitud y moral en Cara de Ángel. Este comienza a ayudar a enemigos y condenados por el poder central, como es el caso de Farfán. 
(...) Se han dado instrucciones al Hospital Militar para que le den un calmante definitivo en la primera borrachera que se ponga de hacer cama. La meretriz que usted frecuenta en El Dulce Encanto informó al Señor Presidente de sus farfanadas revolucionarias. Farfán, a quien las palabras del favorito habían clavado en el suelo, alzó las manos empuñadas.

(...) -No tengo cómo pagar a usted.

-Con el silencio...

-Naturalmente, pero eso no es bastante; en fin, ya habrá ocasión y, desde luego, cuente usted siempre con este hombre que le debe la vida (Asturias 1999, p. 101).

Sin embargo, hay que destacar el precio de su contravención y vincular esto a la forma en que cada vigilante siempre procura ascender en la jerarquía de poder. En capítulos sucedáneos, Farfán, contrario a su promesa y dispuesto a ocupar una mejor posición frente a la centralidad, vende y tortura al ex asesino, lo cual permite por contraste aumentar el valor que tiene el sacrificio y la nueva mirada de Cara de Ángel.

Farfán le saludó desde lejos, le dijo por una de las ventanillas que no se ocupara de sus equipajes, que ahí venían unos soldados a llevárselos al vapor, y al parar el tren subió a estrecharle la mano con vivas muestras de aprecio. Los otros pasajeros se apeaban más corriendo que andando. (...) asomaron a las puertas grupos de soldados con armas. Cara de Ángel comprendió la maniobra demasiado tarde...

-¡De parte del Señor Presidente -le dijo Farfán con el revólver en la mano-, queda usté detenido! (Asturias 1999, p. 153).

Farfán, una vez repuesto en su cargo, no duda en entregar a quien fuese su salvador, lo cual demuestra la calidad acomodaticia de este y otros usuarios del sistema, la falta de lealtad y empatía, márgenes en los cuales la única responsabilidad aceptada es para con el sistema central y su vigilante poder. Lo expuesto se puede resumir en base a lo que Foucault plantea:

El Panóptico puede incluso constituir un aparato de control sobre sus propios mecanismos. (...) El médico incompetente, que haya dejado que se extienda el contagio, el director de prisión o de taller que haya sido torpe, serán las primeras víctimas de la epidemia o del motín. "Mi destino, dice el maestro del Panóptico, está ligado al suyo (al de los detenidos) por todas las ataduras que he podido inventar". El Panóptico funciona como una especie de laboratorio de poder" (Foucault 1998, p. 208).

Como conclusión, se puede agregar que la vigilancia, denuncia y eventual disolución de identidad, causal de pérdida absoluta de cualquier tipo de dominio y titularidad, es capaz de afectar incluso al mismo regidor y cabeza del siniestro modelo. Ya sea víctima de una insurrección interna o por influencias foráneas, producto de la vigilancia y orden emanados de un núcleo mayor, panóptico mundial en el cual el feudo latinoamericano está inserto y supeditado como mera recámara o celda transparente, debido a la intervención de los grandes capitales extranjeros. El siguiente pasaje de la obra resulta clarificador: 
-No me refiero a Canales ni a sus secuaces: ¡la muerte ha sido y será mi mejor aliada, Miguel! Me refiero a los que tratan de influir en la opinión norteamericana con el objeto de que Wáshington me retire su confianza (...) Mi reelección está en peligro y, por eso te he mandado llamar. Necesito que pases a Wáshington y que informes detalladamente de lo que sucede (Asturias 1999, p. 148).

Queda claro tras el análisis que lo perdurable como poder y vigilancia, tanto en la novela como en la ejecución irrestricta del mecanismo a nivel extratextual, es la estructura arquitectónica, el modelo de sociedad y no los ocupantes del mismo, que tan solo se debaten por situarse en una posición favorable ante la centralidad y obtener así una porción de la tan ansiada potestad. Anhelo que sin duda guía los discursos y las relaciones de confidencialidad y confianza al interior de la obra, haciendo de esta no solo la historia de un dictador, sino la gesta de una compleja máquina de poder que determina en virtud de la sutil vigilancia, los límites y destino de la sociedad a la que sirve y, en mayor medida, la identidad y proceder de los individuos que la integran.

\section{A modo de conclusión}

Se puede señalar en concordancia con el análisis y sus objetivos que la obra de Asturias en su tratamiento del poder presenta los elementos tecnológicos que constituyen el diseño arquitectónico de Bentham, pues nos da a conocer un gobierno centralizado, especie de torre que funciona como un sistema administrador de vigilancia, en cuyo interior, jugando el rol de titular, se impone el señor presidente, y a continuación en escalafones menores las fuerzas públicas y sus ayudantes civiles, actuando como una red rotativa de guardias que ejercen su dominio por medio de mecanismos anónimos a fin de delimitar la conducta y conciencia de los reclusos o, en este caso, de los habitantes situados en la periferia del panóptico. Este diseño instaurado a partir de fines del siglo XIII y que opera como medio de normalización, no fue ignorado por Asturias, al constituir el conflicto central de su diégesis y el desarrollo de las múltiples voces asentadas en la ciudad del portal del Señor. Por ello, tras el análisis de la obra y aplicadas las proposiciones postmodernas de Foucault, queda asentada la vigencia del universo represivo que el guatemalteco propone, pues este, en primer lugar, demuestra una crítica dura al proyecto ilustrado y utopía racionalista que termina por convertirse en un núcleo hermético al servicio de unos pocos, tornando al panóptico, un instrumento personalísimo digno de una pesadilla surrealista. En segundo lugar, y en cuanto al ejercicio del poder en nuestra región, podemos destacar problemáticas aún por resolver y que Asturias anticipa. La corrupción, el caudillismo y el intervencionismo que opera por medio de la presión de los grandes capitales extranjeros. En definitiva, la obra puede ser actualizada desde una óptica presente, lo que reafirma la calidad edificante y universal del texto, en la medida en que sus páginas con precisión filosófica y gran dominio estético revelan la construcción de una compleja e interrelacionada maquinaria y lógica, a la cual el lector de hoy puede penetrar para entender a cabalidad la formación y sustentación del poder. 


\section{Referencias bibliográficas}

Albaladejo Mayordomo, Tomás (1989), “La semántica extensional en el análisis del texto narrativo". Teorías literarias en la actualidad. Madrid: Arquero; pp. 194195.

Asturias, Miguel Ángel (1999), El Señor Presidente. Madrid: Unidad Editorial. (2000), El Señor Presidente. Edición crítica de Gerald Martin. Barcelona: Galaxia Gutenberg, Círculo de Lectores.

Bellini, Giuseppe (1999), Mundo mágico y mundo real: la narrativa de Miguel Ángel Asturias. Italia: Bulzoni Editore.

Bentham, Jeremías (1989), El Panóptico. Ediciones Endimión.

Calviño Iglesias, Julio (1985), La novela del dictador en Hispanoamérica. Madrid: Ediciones Cultura Hispánica, Instituto de Cooperación Iberoamericana.

Foucault, Michel (1980), “El ojo del poder”, en El panóptico. Madrid: Ediciones La Piqueta. XXI.

(1998), Vigilar y castigar. El nacimiento de la prisión. México: Siglo

Goic, Cedomil (1972), Historia de la novela hispanoamericana. Santiago de Chile: Ediciones Universitarias de Valparaíso.

González Echevarría, Roberto (1985), The Voice of the Masters: Writing and Authority in Modern Latin American Literature. Austin, Texas: University of Texas Press.

Saúl Hurtado Heras (2003), "Vida/Muerte: de la dicotomía existencial a la pugna por el poder en la narrativa de Miguel Ángel Asturias", Espéculo. Revista de estudios literarios. Universidad Complutense de Madrid, Número 25.

Leal, Luis (1995), Magic Realism in Spanish American Literature. Duke University Press, pp. 119-124.

Martin, Gail (2000), "Manuel Estrada Cabrera 1898-1920: El Señor Presidente”, en Gerald Martin (ed.), El Señor Presidente por Miguel Ángel Asturias, Critical ed. Barcelona: Galaxia Gutenberg Círculo de Lectores.

Sartre, Jean Paul (1966), El Ser y la Nada. Buenos Aires: Losada.

Silva de Velásquez, Caridad(1977), “Desarrollo y función del paralelo políticorreligioso en El señor Presidente", Actas del VI Congreso de la Asociación Internacional de Hispanistas. Toronto: Ont., pp. 707-711. 